\title{
Monochromatic blue light entrains diel activity cycles in the Norway lobster, Nephrops norvegicus (L.) as measured by automated video-image analysis
}

\author{
JACOPO AGUZZI ${ }^{1}$, CORRADO COSTA ${ }^{2}$, PAOLO MENESATTI ${ }^{2}$, \\ JOSÉ ANTONIO GARCÍA ${ }^{1}$, JUAN JOSÉ CHIESA ${ }^{3}$ and FRANCESC SARDÀ ${ }^{1}$ \\ ${ }^{1}$ Institut de Ciències del Mar (ICM-CSIC), Passeig Marítim de la Barceloneta 37-49, 08003 Barcelona, Spain. \\ E-mail: jaguzzi@cmima.csic.es \\ ${ }^{2}$ AgritechLab - Agricultural Engineering Research Unit of the Agriculture Research Council (CRA-ING), \\ Via della Pascolare, 16, C.A.P. 00016 Monterotondo, Roma, Italy. \\ ${ }^{3}$ Laboratorio de Cronobiología, Departamento de Ciencia y Tecnología, Universidad Nacional de Quilmes - CONICET, \\ Roque Sáenz Peña 352, B1876BXD Bernal, Buenos Aires, Argentina.
}

SUMMARY: There is growing interest in developing automated, non-invasive techniques for long-lasting, laboratory-based monitoring of behaviour in organisms from deep-water continental margins which are of ecological and commercial importance. We monitored the burrow emergence rhythms in the Norway lobster, Nephrops norvegicus, which included: a) characterising the regulation of behavioural activity outside the burrow under monochromatic blue light-darkness (LD) cycles of $0.11 \mathrm{x}$, recreating slope photic conditions (i.e. 200-300 m depth) and constant darkness (DD), which is necessary for the study of the circadian system; b) testing the performance of a newly designed digital video-image analysis system for tracking locomotor activity. We used infrared USB web cameras and customised software (in Matlab 7.1) to acquire and process digital frames of eight animals at a rate of one frame per minute under consecutive photoperiod stages for nine days each: LD, DD, and LD (subdivided into two stages, LD1 and LD2, for analysis purposes). The automated analysis allowed the production of time series of locomotor activity based on movements of the animals' centroids. Data were studied with periodogram, waveform, and Fourier analyses. For the first time, we report robust diurnal burrow emergence rhythms during the LD period, which became weak in DD. Our results fit with field data accounting for midday peaks in catches at the depth of slopes. The comparison of the present locomotor pattern with those recorded at different light intensities clarifies the regulation of the clock of $N$. norvegicus at different depths.

Keywords: digital-video image analysis, thresholding, automation, monochromatic blue light, constant darkness, Nephrops norvegicus, locomotor activity.

RESUMEN: LA LUZ MONOCROMÁTICA AZUL ENCARRILA EL RITMO DE ACTIVIDAD EN LA CIGALA NEPHROPS NORVEGICUS (L.) COMO MEDIDO A TRAVÉS DEL ANÁLISIS AUTOMATIZADO DE VIDEOS DIGITALES. - Existe un interés creciente en el desarrollo de técnicas automatizadas y no invasivas para el seguimiento a largo plazo y en condiciones de laboratorio de la actividad conductual en organismos que habitan los márgenes continentales. En este trabajo, hemos hecho un seguimiento de los ritmos de emergencia de la madriguera en la cigala, Nephrops norvegicus, incluyendo: a) la caracterización de la respuesta locomotora bajo ciclos de luz-oscuridad (LO; $480 \mathrm{~nm}$ ) de $0.1 \mathrm{~lx}$, recreando las condiciones fóticas del talud (200-300 m de profundidad), y bajo condiciones de oscuridad constante (OO), necesarias para la caracterización del sistema circadiano; b) la puesta a punto de un sistema novedoso de análisis digital de video para el seguimiento de la actividad locomotora. Se emplearon cámaras web con transmisión USB y un software diseñado en Matlab 7.1, para la adquisición y el procesamiento de imágenes de ocho animales con un muestreo de un cuadro por minuto, a lo largo de etapas consecutivas: LO, OO, y LO (9 días cada etapa; LO final denominados LO1 y LO2 para el análisis). Se generaron automáticamente series temporales de actividad locomotora basadas en el cálculo del centroide de los animales y su desplazamiento. Por primera vez se detectó la presencia de robustos ritmos diurnos de emergencia de la madriguera en LO, que se debilitan en condiciones de OO. Estos resultados se corresponden con los obtenidos en el campo, considerando que los picos de captura ocurren al mediodía en las profundidades del talud (400-430 m). La comparación de los patrones locomotores obtenidos en este trabajo con aquellos registrados bajo diferentes intensidades lumínicas, clarifica aspectos de la regulación del sistema circadiano de $N$. norvegicus en diferentes profundidades.

Palabras clave: análisis de videos digitales, filtrados automación, luz monocromática azul, obscuridad constante, Nephrops norvegicus, actividad locomotora. 


\section{INTRODUCTION}

The Norway lobster, Nephrops norvegicus, is an ecologically and commercially important crustacean decapod of the Atlantic and Mediterranean shelves and slopes (reviewed by Bell et al., 2006; Aguzzi and Sardà, 2008). Animals inhabit individual burrows used to exert territorial control. Temporally scheduled trawl tows have identified robust diel fluctuations in catches produced by a modulation of species burrow emergence behaviour over the 24-hour period. Peaks in catches varied from nocturnal to crepuscular, moving from the upper to lower shelves (Andersen 1962; Farmer, 1974; 1975; Chapman et al., 1972, 1975; Oakley 1979; Moller and Naylor, 1980). On slopes, emergence rhythmicity was fully diurnal (Aguzzi et al., 2003; Cristo and Castro, 2005).

Chapman et al. (1972, 1975) proposed that animals set their burrow emergence for the same optimum environmental illumination that occurs at different times of the day at different water depths, depending on the position of the sun and, thus, on penetration of light into the water column. Since the spectral diversity of light decreases with depth, Aguzzi et al. (2008) proposed that blue monochromatic radiation (i.e. $480 \mathrm{~nm}$ ) chiefly modulates species behaviour. This high energy radiation is invariably present on both shelves and slopes (Jerlov, 1979; Herring 2002). It is the putative synchroniser for diel rhythms in several deep-water continental margin decapods with wide depth ranges of distributions (including $N$. norvegicus). Apparently, blue light is a synchroniser of decapod activity rhythms since it acts on extraocular photoreceptors containing blue photopigments (i.e. CRY) and located in the protocerebrum (i.e. the brain) (Fanjul-Moles et al., 2004).

Only $30 \%$ of $N$. norvegicus perform burrow emergence on a diel basis as estimated by different sampling systems of trawling and direct underwater burrow counting (Chapman, 1980). In this context, laboratory studies on behavioural rhythms are of importance for the fishery management of this species, since such data provide a comparison for demographic estimations obtained in the field via trawling. Until recently, laboratory studies were always undertaken by means of actigraphy over short periods of time (e.g. Atkinson and Naylor, 1976; Aréchiga et al., 1980; Moller and Naylor, 1980; Aguzzi et al., 2004; Aguzzi et al., 2008). None of these studies were performed under blue-monochromatic light cycles of variable light intensity simulating slope depths (Aguzzi and Sardà, 2008).

There is a growing interest in developing automated, non-invasive techniques for the long-lasting monitoring of the behaviour of marine organisms that are of ecological and commercial importance (Naylor, 2005). For studies on biological rhythms, actigraphic and telemetric devices are currently the tools most used (see review by Refinetti, 2006). However, these methods can only provide information on parameters in gross locomotor rhythmicity, such as periodicity and phase. No quantification of activity status parameters, such as total recurred distances during activity, can be precisely computed (Costa et al., 2006). In this work, our aims in relation to $N$. norvegicus burrow emergence behaviour were the following: a) to characterise its rhythmic expression under monochromatic blue light-darkness cycles of $0.1 \mathrm{~lx}$, approximately recreating photic conditions at 200-300 m depth (Aguzzi et al., 2003), as well as under constant darkness, an important experimental protocol for investigating rhythm functioning for chronobiological studies (i.e. the testing of endogenous periodicities); and b) to describe and test the performance of a newly customised and low-cost automated digital video-image analysis system for the prolonged tracking of $N$. norvegicus emergence behaviour.

\section{MATERIALS AND METHODS}

\section{Animal housing}

Eight adult male lobsters with mean carapace lengths of $37.5 \pm 4.4 \mathrm{~mm}$ (see Table 1 ) were used in our experiment. Animals were collected by a commercial trawler operating off the Ebro delta (northwestern Mediterranean; $40^{\circ} 39^{\prime} \mathrm{N}, 1^{\circ} 13^{\prime} \mathrm{E}$; $\left.40^{\circ} 38^{\prime} \mathrm{N}, 1^{\circ} 11^{\prime} \mathrm{E}\right)$ at a depth of approximately 80-100 m (Aguzzi et al., 2003). In order to avoid retinal damage upon exposure to sunlight (Gaten et al., 1990), trawl sampling at night and all deck operations were performed under dim red light (i.e. $<1$ lx). Animals were immediately transferred to dark, refrigerated containers with constant aeration of the water. Laboratory acclimation was carried out over one month prior to the experiment in a light-proof isolated chamber under the following conditions: i) constant temperature of $13^{\circ} \mathrm{C} \pm 0.1^{\circ} \mathrm{C}$ (i.e. as corresponds to the bottom tem- 
TABLE 1. - Biological information referring to animal code, carapace length (CL, mm), significant locomotor periodicity (T, hours) and average burrow occupancy ( $\min \pm \mathrm{SD}$ ) for Nephrops norvegicus surveyed over one month under different stages of blue monochromatic light-darkness conditions (initial light-darkness, LD; constant darkness, DD; and finally, re-established light-darkness periods LD1 and LD2). Arrhythmia (ARR) in time-series of data is also indicated.

\begin{tabular}{|c|c|c|c|c|c|c|c|c|c|}
\hline \multirow{2}{*}{$\begin{array}{l}\text { Animal } \\
\text { Code }\end{array}$} & \multirow[b]{2}{*}{ CL } & \multicolumn{4}{|c|}{$\mathrm{T}(\mathrm{h})$} & \multicolumn{4}{|c|}{ Burrow occupancy } \\
\hline & & LD & DD & LD1 & LD2 & LD & DD & LD1 & LD2 \\
\hline A & 41.5 & 24.1 & ARR & 24 & 23.5 & $643.8 \pm 86.3$ & $480.0 \pm 46.9$ & $878.8 \pm 70.6$ & $753.8 \pm 83.7$ \\
\hline B & 31.7 & 24 & 24 & 24 & 24 & $460.0 \pm 57.3$ & $426.3 \pm 110.2$ & $590.0 \pm 53.2$ & $437.5 \pm 159.8$ \\
\hline $\mathrm{C}$ & 35.2 & 23.9 & ARR & 24 & 24 & $387.5 \pm 61.1$ & $355.0 \pm 69.5$ & $367.5 \pm 96.2$ & $203.8 \pm 54.0$ \\
\hline $\mathrm{D}$ & 32.9 & ARR & 24 & 23.8 & ARR & $1257.5 \pm 140.1$ & $1227.5 \pm 85.6$ & $1336.3 \pm 84.0$ & $1298.8 \pm 41.2$ \\
\hline $\mathrm{E}$ & 35.5 & 24 & ARR & 24 & 24 & $538.8 \pm 103.7$ & $457.5 \pm 97.5$ & $392.5 \pm 100.4$ & $467.5 \pm 139.2$ \\
\hline $\mathrm{F}$ & 38.9 & ARR & ARR & 24.6 & 23.7 & $1425.0 \pm 20.0$ & $1412.5 \pm 10.4$ & $1393.8 \pm 45.3$ & $1432.5 \pm 7.1$ \\
\hline G & 39.8 & 24 & ARR & ARR & ARR & $60.0 \pm 28.3$ & $43.8 \pm 21.3$ & $43.8 \pm 37.8$ & $28.8 \pm 23.0$ \\
\hline $\mathrm{H}$ & 44.4 & 24 & ARR & 23.8 & 24.2 & $20.0 \pm 12.0$ & $12.5 \pm 12.8$ & $5.0 \pm 10.7$ & $2.5 \pm 4.6$ \\
\hline Mean & 37.5 & 24.0 & 24.0 & 24.0 & 23.9 & & & & \\
\hline SD & 4.4 & 0.1 & 0.0 & 0.3 & 0.3 & & & & \\
\hline
\end{tabular}

perature on the continental shelf throughout the year; Salat, 1996); and ii) a monochromatic (480 nm) blue light-darkness regime of $0.1 \mathrm{~lx}$, simulating approximately light intensity conditions at 200-300 $\mathrm{m}$ depth (Aguzzi et al., 2003). Monochromatic blue light was chosen to fit the maximum absorbance of the visual pigments of $N$. norvegicus (Loew, 1974), and thus recreated the photic environment required for the proper recording of animal behavioural rhythms during emergence (reviewed by Aguzzi et al., 2008). Photophase duration lasted for 12 hours, starting and ending at 7:00 and 19:00 h, respectively. Full light intensity was acquired within 30 minutes in order to acclimatise the lobsters' eyes and avoid optical damage (Gaten et al., 1990).

\section{Experimental settings}

At the beginning of testing, each animal was placed in a polycarbonate aquarium. Each tank recreated selected environmental features of $N$. norvegicus grounds, such as the burrows (entrance and tunnel diameters of $10 \mathrm{~cm}$ and $7 \mathrm{~cm}$, respectively; tunnel length of $25 \mathrm{~cm}$; angular inclination of burrow entrance of $20^{\circ}$ ) with a terminal ventilator shaft $(0.4 \mathrm{~cm}$ of diameter) and substratum simulating the sediment, made by synthetic acrylic glued to the aquarium base.

Blue $(480 \mathrm{~nm})$ monochromatic photodiodes were mounted in transversal plates on top of the aquaria in order to provide a direct and diffuse source of illumination. Light cycles followed the temporal scheduling of the acclimation period. Locomotor testing was performed over consecutive stages of 9 days each, as follows: light-darkness (12L:12D; $0.1 \mathrm{~lx})$; constant darkness (DD; 0 lx); and finally, light-darkness under equivalent conditions to the beginning stage for 18 days with that period sub-divided into two stages, LD1 and LD2, in order to assess variations in emergence behaviour for spatial habituation (Aguzzi et al., 2008). The total duration of the experiment was 36 days, and animals were not fed during tests to prevent synchronisation of activity rhythms upon feeding timing (Fernández de Miguel and Aréchiga, 1994; Aguzzi et al., 2005, 2006).

Eight digital CMOS web cameras (F.2.0.301L; Creative) were connected to a PC by a multi-port USB in order to perform sequential frame acquisition. Web cameras were mounted on an extendable arm (Fig 1A) along the side of the aquarium, in order to obtain a full lateral view of animal activity outside the burrow. Cameras were provided with a constantly functioning source of infrared illumination form LEDs (i.e. $930 \mathrm{~nm}$ ). N. norvegicus is not sensitive to that wavelength (Loew, 1974), so this type of illumination does not represent a source of photic interference in studies on biological rhythms under different photoperiod schedules, allowing for video-filming operations during darkness. Cameras acquired one frame per minute. Frames were stored with high quality (85\%) in JPEG format at an optical resolution of $640 \times 480$ pixels.

\section{Image analysis processing}

Digital video-image analysis was performed in Matlab 7.1 with the Image Processing toolbox. The optimisation of the automation in the analysis was obtained by identifying a priori a region of interest (ROI; Fig. 1B) within each field of view (FOV) of the web cameras. An ROI of $60 \mathrm{~cm}$ length, $20 \mathrm{~cm}$ width, and $25 \mathrm{~cm}$ height encompassing the lateral 

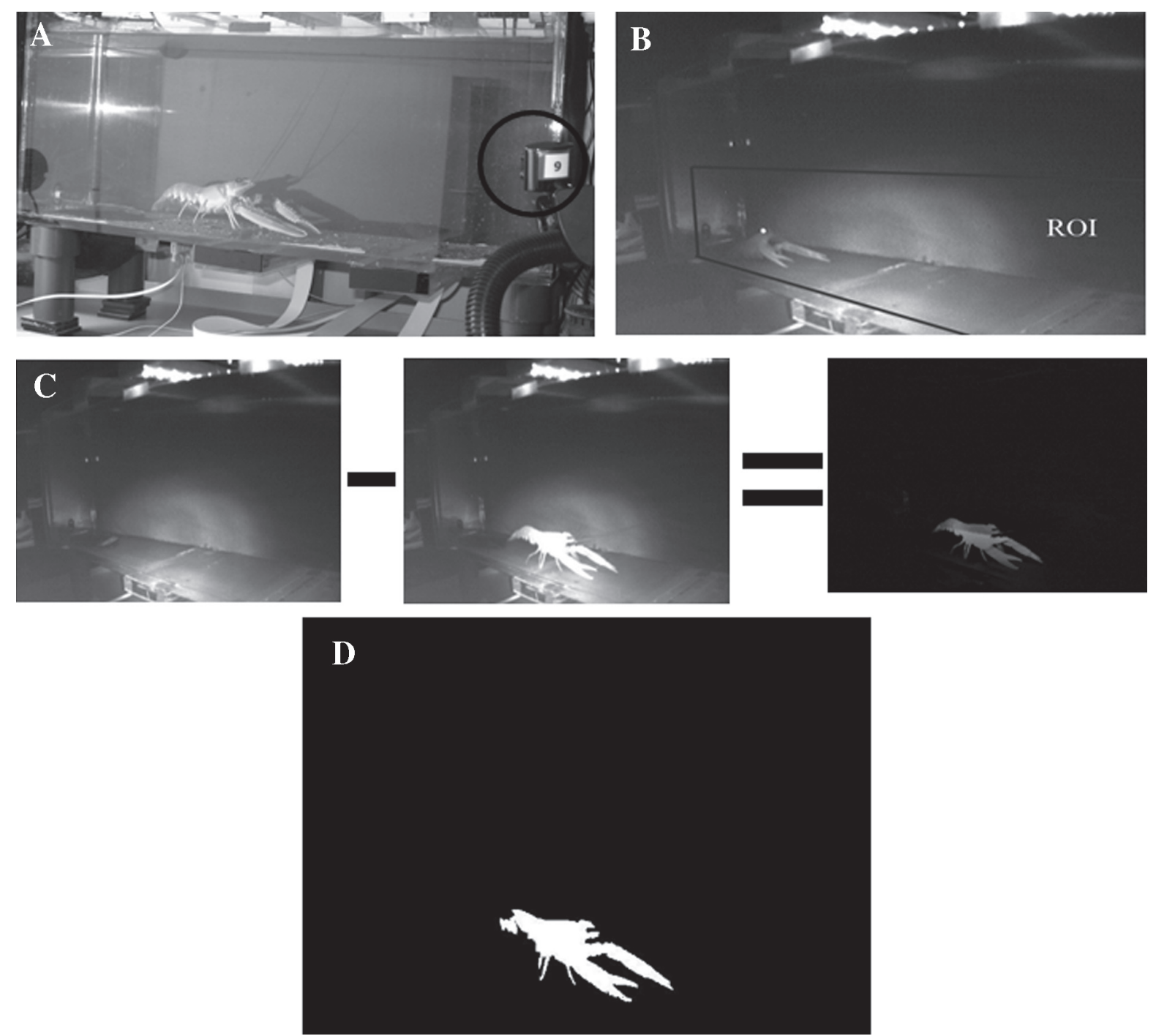

FIG. 1. - Different and consecutive steps of the analysis of automated digital video-image analysis used to determine burrow emergence rhythms in Nephrops norvegicus. The lateral view of the aquarium (A) is visible along with the used digital-video camera (i.e. in the black circle). The region of interest (ROI; B) was selected prior to the start of the analysis in order to define the field in which pixel differences between temporally consecutive frames (C) are measured. Images resulting from pixel subtraction (D) are filtered by grey scale in order to enhance the profiles of animals and compute the centroid.

FOV of each aquarium was chosen. A side, not vertical, FOV was chosen to avoid interferences in image processing produced by movements of the water surface. An instantaneous field of view (IFOV), as the spatial resolution taken by single pixels, was calculated for the whole ROI considering the aquarium position. In this manner, pixels could be converted into centimetres.

Animal motion analysis was performed by means of algebraic subtraction of two consecutive images as numerical matrixes of pixel values at 256 different levels of grey (Fig. 1C). A thresholding of the resulting matrix for a minimum value of body area (A) and grey level $(\mathrm{G})$ was performed in order to identify the body position (Fig. 1D), eliminating all surrounding noise that was not created by the movement of the animal. That threshold is a filtering process consisting of the removal of small pixel blocks to determine the animal image boundaries (Shih and Young, 2007). After the algebraic subtraction, the preceding frame was automatically eliminated in order to avoid the constraint of PC memory size. Images of the eight animals were acquired in a sequential fashion in order to minimize the time lag between consecutive frames. Then, each frame and its precedent for an animal were processed by a customized Matlab script in approximately 1.2. Elaboration was done on blocks of images saved per 24 hours, but we also implemented and tested a script that allowed the whole process to be on-line. 
The movement of animals was estimated by identifying the centre of the body area (i.e. the $\mathrm{x}, \mathrm{y}$ centroid coordinates) in the subtracted images. When the animal was hidden inside the burrow, the centroid was considered to be a fixed point corresponding to the centre of the burrow mouth. Accordingly, values of centroid displacement equal to 0 indicated burrow occupancy. Animals were considered absent until the moment when the eye was visible. Metric distances were calculated in Excel by applying a conversion matrix between pixel and IFOV size.

Correct values of $A$ and $G$ were identified during a training procedure that consisted in the visual inspection of 500 consecutive, randomly chosen frames (i.e. the training set) for an animal. An operator annotated the presence/absence of the animal in each picture of the set. Results were then compared to data obtained by analyzing the same set with an automated procedure that was repeated 2500 times, varying the value of $A$ and $G$ at each repetition. The percentage of identification error between the visual inspection and the image analysis procedure was then calculated at each repetition. The values of $\mathrm{A}$ and $\mathrm{G}$, corresponding to the minimum identification error, were then taken as reference for the whole procedure of image analysis.

\section{Data treatment and analysis}

Raw data of locomotor events, such as centroid movement (in centimetres) per minute, were summed up in a $10 \mathrm{~min}$ bin. This provided recompiled time series for eliminating high-frequency noise, thus enhancing behavioural patterns (Levine et al., 2002). Resulting data sets were then treated with different statistic tools of chronobiology in order to demonstrate the efficiency of the applied technology for the study of rhythmic behaviour of $N$. norvegicus. First, time series were represented in the domain of time by means of double-plot histograms of activity (i.e. actograms). In these plots, consecutive data were placed in columns, and activity was reported per 24 hours in duplicate, resulting in easier identification of the phases of detected rhythms with the imposed light-darkness cycle.

Periodogram analysis was performed separately for all time-series segments, corresponding to each stage (LD, DD, LD1, and LD2). Significant $(P<0.05)$ periodicities were screened between 10 and $30 \mathrm{~h}$ by $\chi^{2}$ periodogram software (Clock Lab; Actimetrics, Evanston, IL). The temporal window of screening was chosen to detect both ultradian and circadian locomotor rhythms (Aguzzi et al., 2003; Aguzzi and Chiesa, 2005). In the resulting periodogram plots, the highest significant peak corresponded to the maximum percentage of total data variance explained by the inherent periodicity (Canal-Corretger et al., 2001). The value of that peak was chosen for period estimation.

Waveform analysis was undertaken to precisely assess the phase of the emergence rhythms. For each individual, portions of time-series corresponding to each stage were extracted and subdivided into 24-h segments. Then, values were averaged per day segment in the corresponding bin, to provide a consensus mean waveform. Mean waveforms were plotted with imposed photophase temporal limits to visualise the agreement of emergence behaviour with day or night.

Time-series were studied in the frequency domain by means of serial Fourier analysis, which allowed rhythm period changes to be described by modelling a priori harmonic components and then fitting these to data sets from different animals at each experimental stage. A fundamental harmonic, with a period of $24 \mathrm{~h}$ and 9 sub-multiples, was used to cover the circadian harmonic and a wide array of ultradian periodicities. The power content (PC) is the capability of each modelled harmonic to fit (by least square fitting) the real locomotor data set. PC values for each of the modelled harmonics were obtained. At each experimental stage, PC values for the ultradian harmonics were summed up to constitute the ultradian band. Thus, PC values for both the circadian harmonic and the ultradian band were averaged at each stage for all animals and then plotted with standard errors. One-way ANOVA analysis was used to assess the occurrence of significant differences in PC for the circadian component and the ultradian band over different experimental stages. Prior to the ANOVA, assumptions for normality and homogeneity of data sets were verified (Kolmogorov-Smirnoff test, $P>0.05$; Bartlett test, $P>0.05$ ).

The total time spent by animals in their burrows per day (i.e. burrow occupancy) was estimated by counting time-series values equivalent to 0 per 24 $\mathrm{h}$ segments. Then, a mean count was computed for each experimental stage by averaging day values. Total recurred distance during out-of-burrow activity was computed for each animal per day. Values were summed up every 24 hours and represented by consecutive days for all stages. 


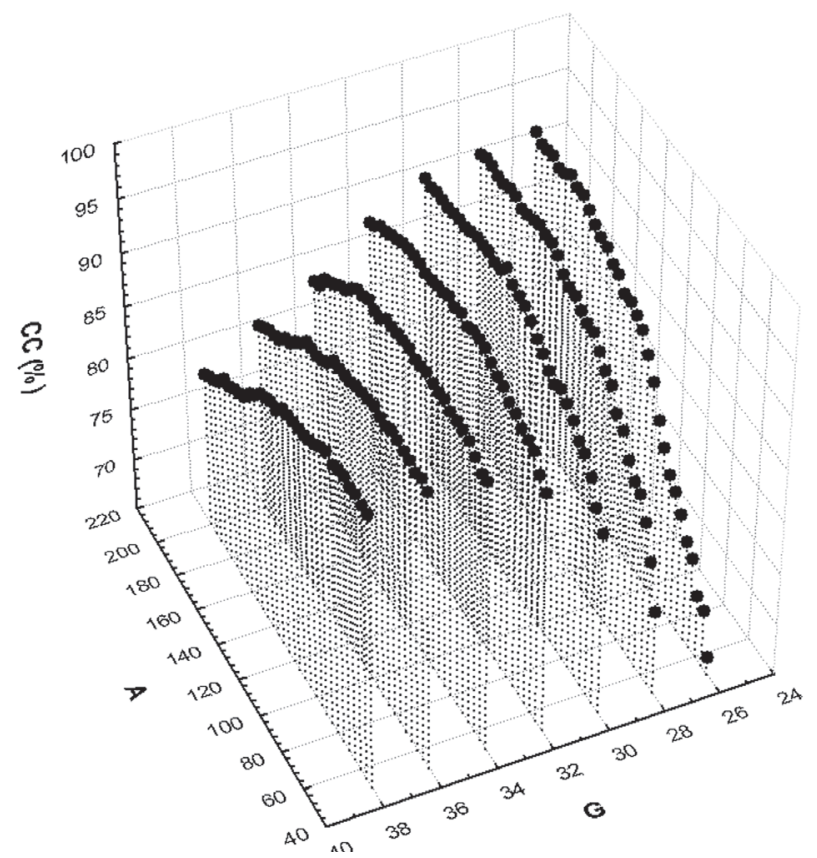

FIG. 2. - Percentage of correct classification (CC) at each starting trial for different levels of body area (A) and grey level (G) is presented as an indication of the process of efficiency calibration in the automated analysis of consecutive digital frames.

\section{RESULTS}

The detection system based on infrared USB web cameras continuously acquired frames for all animals over 36 days. The automated analysis of frames was used to produce locomotor time-series based on movements of centroids for all tested individuals. The performance of movement identification, as calculated considering the training procedure (Fig. 2 ), reached $94 \%$ correct classification when $A=130$ (pixel area) and $\mathrm{G}=30$ (grey level).

Of a total of 8 animals, 6 demonstrated marked diel rhythms during the first period of locomotor testing under a light-darkness (LD) cycle (i.e. average periodicity of $24.0 \pm 0.1 \mathrm{~h}$; see Table 1). Only two individuals showed arrhythmia at this experimental stage. Conversely, when transferred to constant darkness (DD), the majority of tested animals became arrhythmic, and only 2 of the 8 animals demonstrated circadian rhythmicity (i.e. average periodicity of $24.0 \pm 0.1$ h). This was visible in double-plot actograms shown in Fig. 3A, and the activity of two animals is shown as an example in Fig. 3B. In these plots, the circadian rhythmicity is weak during the DD stage, as confirmed by corresponding periodogram analysis, and rhythms start to free-run during approximately the last three days of this stage (see animal in Fig. 3B). After re-exposure to the original photoperiod schedule (i.e. stages LD1 and LD2), the rhythmicity of animals reacquired a robust diel character (i.e. $24.0 \pm 0.3 \mathrm{~h}$ for LD1; $23.9 \pm 0.3 \mathrm{~h}$ for LD2). Arrhythmic animals were the minority in both stages, with only one occurring in LD1 and two in LD2.

Waveform analysis indicated the occurrence of fully diurnal burrow emergence behaviour in LD, LD1, and LD2 for the majority of the tested animals. Sudden increases and decreases in locomotor activity outside the burrow occurred at light-ON and -OFF, respectively (see Fig. 3A, B), being reported as activity. During DD, all animals showed lessdefined waveform patterns, despite the detection in some cases of weak circadian rhythmicity in periodogram analysis (e.g. Fig. 3A). Interestingly, one animal showed a phase inversion in behavioural activity after the re-exposure to light-darkness conditions (i.e. from DD to LD1; Fig. 3A). This animal showed nocturnal activity with a weaker peak in LD1, which was more compacted during LD2. This was also reflected by SD units in periodogram plots, as a measure of the rhythm's strength. That animal in LD2 was trying to regain its diurnal activity by increasing the frequency of locomotor rhythmicity over consecutive days. In fact, periodogram analysis indicated a diel periodicity equivalent to $23.5 \mathrm{~h}$, which was also visible through the corresponding double-plot actogram.

Fourier analysis (Fig. 4) indicated that animal behaviour showed a dominant circadian component when initially exposed to LD. Upon transference to DD, the 24-h harmonic clearly diminished, and it was re-established under further exposure to LD conditions (i.e. $\mathrm{LD}_{1}$ and $\mathrm{LD}_{2}$ ). The change in $\mathrm{PC}$ over different experimental stages was significant only for the circadian component, when LD was compared with DD (one-way ANOVA; $P<0.05$ ). The PC of the ultradian band did not show significant changes over different experimental stages.

High variability in burrow occupancy was reported among all surveyed animals (see Table 1). Out of 8 animals, only 2 individuals performed very poor emergence behaviour at any stage of testing (i.e. animals nos. D and F spent close to 24 hours in the burrow). The other two individuals (i.e. animals nos. $\mathrm{G}$ and $\mathrm{H}$ ), demonstrated the opposite behaviour of poor burrow occupancy and were always present outside their burrows.

Consequently, high inter-individual variability was also observed in relation to distances covered 

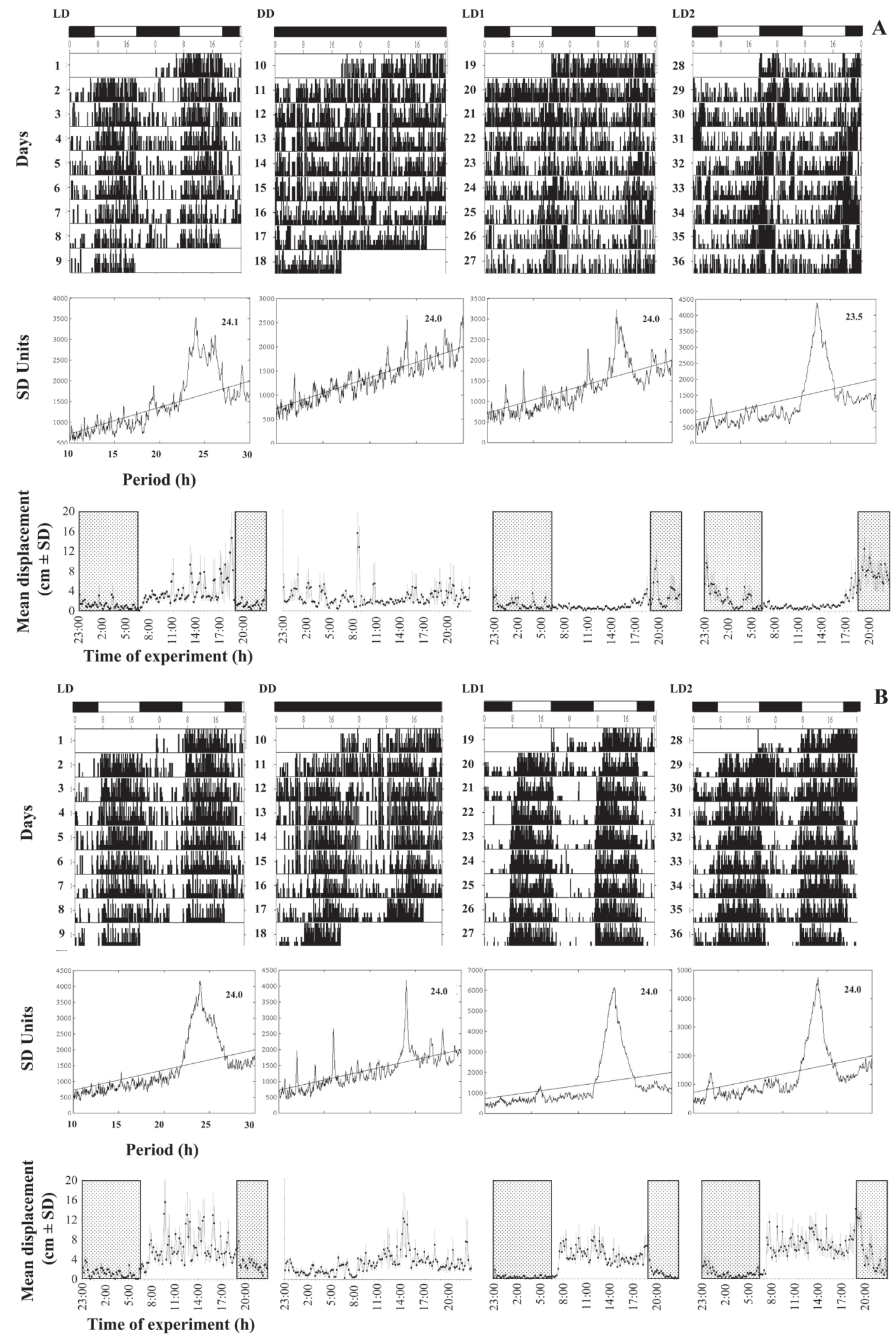

FIG. 3. - Outputs of time-series analysis on locomotor activity of two individuals (A and B; see Table 1 ) continuously surveyed over 36 days under different photoperiod conditions (initial light-darkness, LD; constant darkness, DD; and finally, re-established light-darkness periods LD1 and LD2). Double-plot actograms are in the upper area (i.e. black bars indicate the night duration); periodogram plots are in the middle area; and waveforms are reported at the bottom (i.e. shaded grey rectangles are the night duration). 


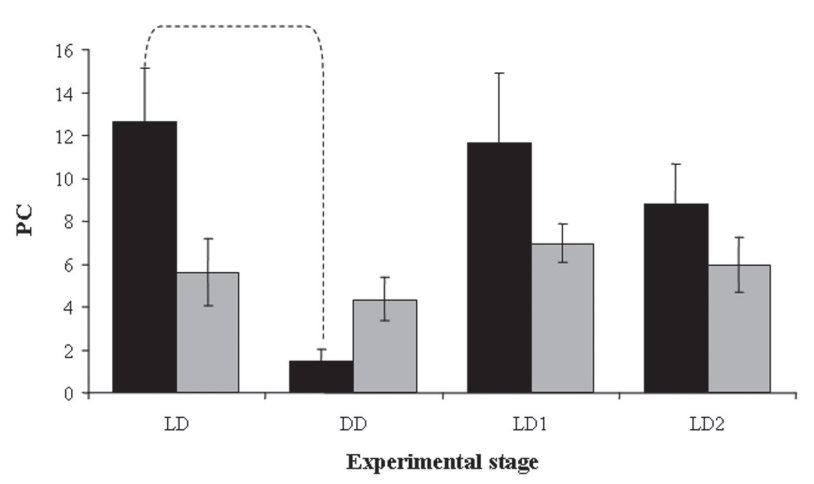

Fig. 4. - Mean $( \pm$ SD) power content $(\mathrm{PC})$ values measured for the circadian harmonic (i.e. black) and for the ultradian harmonic band (i.e. grey), as estimated from Fourier analysis of 24-h data segments in each experimental stage for all animals (initial light-darkness, LD; constant darkness, DD; and finally, re-established light-darkness periods LD1 and LD2). The dashed line indicates a significant decrease (from ANOVA analysis) of circadian component PC at animal transference from LD to constant DD.

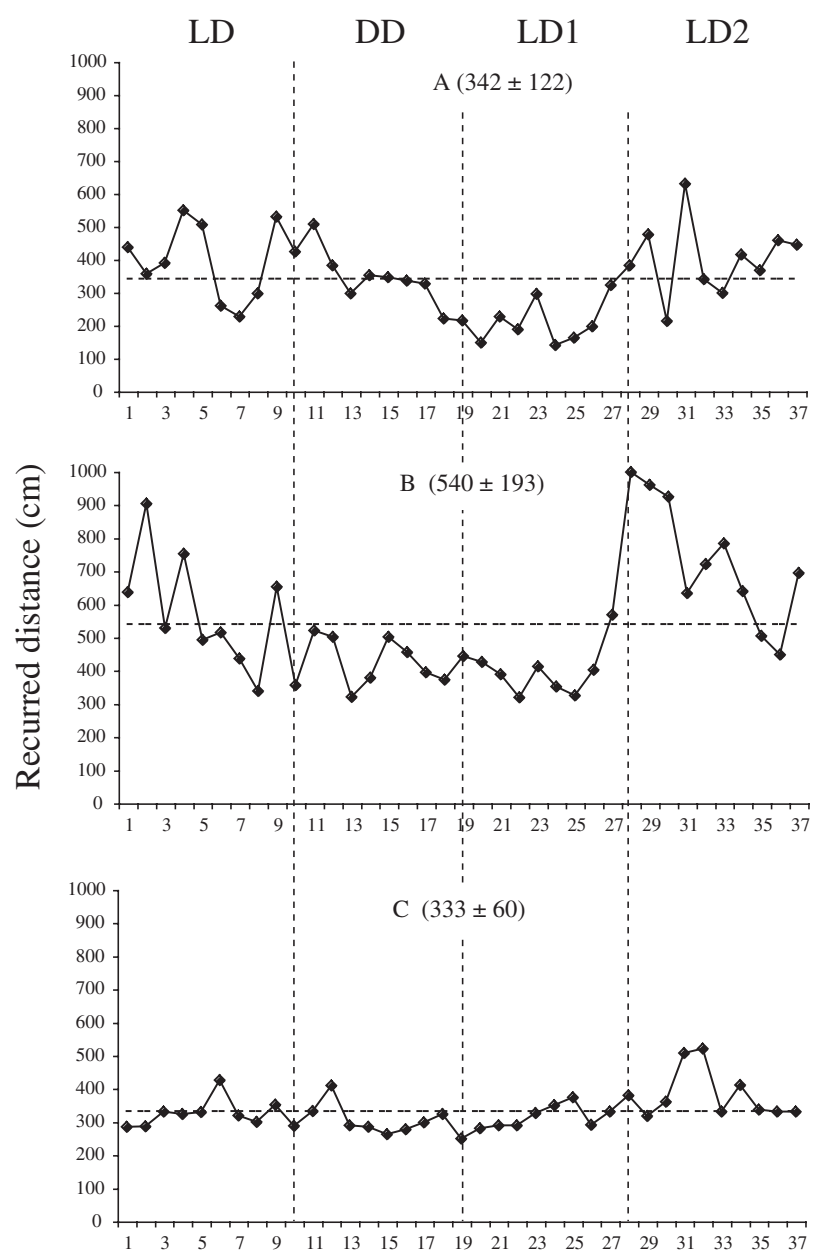

per day (Fig. 5). Generally, the range of movement for individuals varied from an absolute minimum of $139.8 \mathrm{~cm}$ (animal no. 1 during the $24^{\text {th }}$ day) to an absolute maximum of $1917.1 \mathrm{~cm}$ (animal no. 8, during the $4^{\text {th }}$ day).

\section{DISCUSSION}

In this study, we have reported strong diurnal burrow emergence rhythms in isolated individuals under a monochromatic blue light-darkness cycle of $0.1 \mathrm{~lx}$. With applied photoperiod conditions, we efficiently recreated in the laboratory at the level of single individuals the catchability patterns displayed by populations of slopes. Taken together, the present results indicate that blue light is an efficient zeitge-

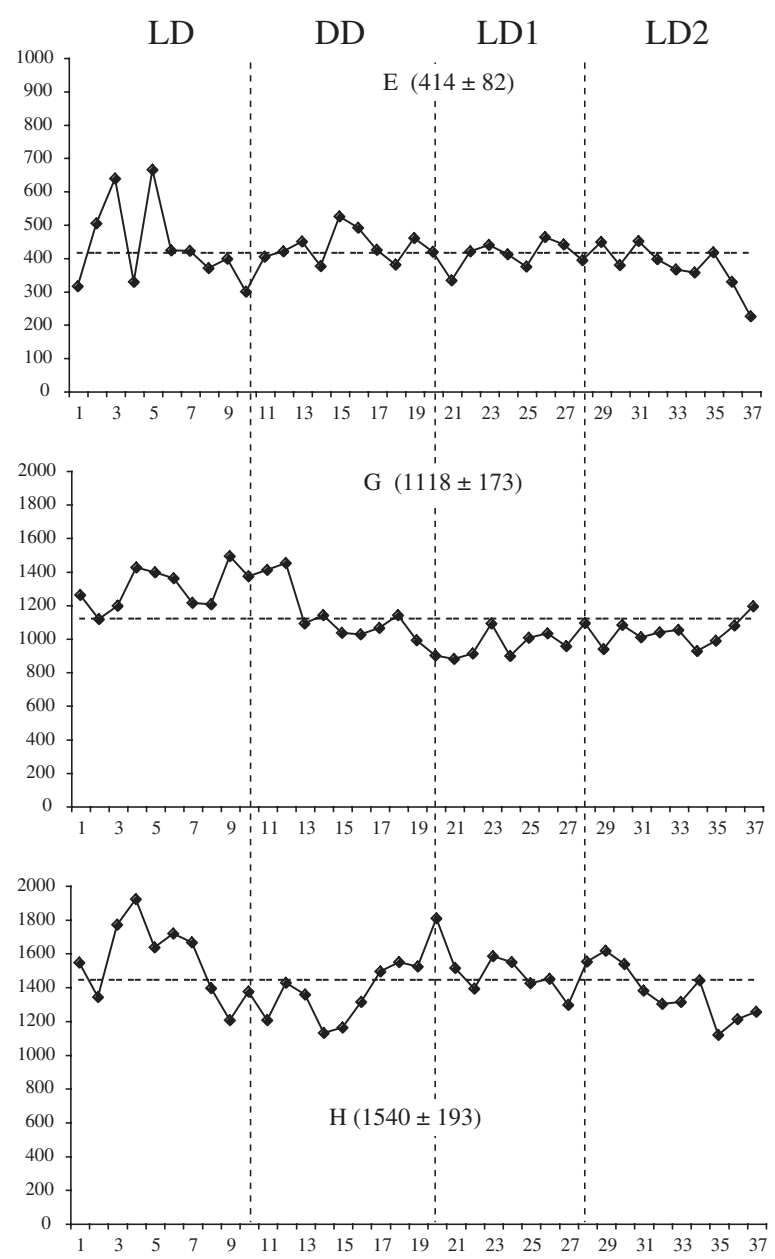

Time of experiment (days)

FIG. 5. - Total distance covered per day is reported for six animals with the exception of two that performed poor burrow emergence (i.e. animals D and F, see burrow occupancy data in Table 1). Vertical dashed lines indicate experimental stage boundaries (i.e. initial light-darkness, LD; constant darkness, DD; and finally, re-established light-darkness periods LD1 and LD2). Horizontal dashed lines are averaged values of distance computed over 37 days as a global measure of mean $( \pm \mathrm{SD})$ displacement (the value is reported beside the animal code in the plot). 
ber for the setting of behavioural rhythms in N. norvegicus at markedly different depths of continental margins. Also, the occurrence of alternation between scoto- and photophase is required by animals in order to express a robust locomotor activity rhythm, since rhythmicity weakens in constant darkness.

Under the present photic conditions (approximately simulating 200-300 $\mathrm{m}$ depth), emergence is diurnal, while for an increase in the intensity animals leave their burrows at night. The comparison of the present data with those presented by Aguzzi et al. (2008) under the same photoperiod cycle but with an increased intensity (i.e. $5 \mathrm{~lx}$; simulating 80-100 $m$ depth), indicates that burrow emergence in the laboratory can be temporally shifted, similarly to what was observed in field catch patterns at different depths of continental margins (Aguzzi et al., 2003).

Loew (1974) found that the maximum absorption of the visual pigment of $N$. norvegicus was at 498 $\mathrm{nm}$, i.e. in the blue-green part of the spectrum. However, we showed a response of behavioural rhythms to monochromatic $(480 \mathrm{~nm})$ blue light cycles. This occurs since the processes of vision and biological clock entrainment follow different input pathways in decapods (and other invertebrates such as the fruit fly, Drosophila melanogaster) (Edwards, 1984; Cronin, 1986; Emery et al., 2000): the eyes are responsible for vision; extraocular photoreceptors in the cephalothorax, protocerebrum, and abdominal ganglia are used for the entrainment of the biological clock (which generates and controls behavioural rhythms). If vision occurs for wavelengths ranges close to $498 \mathrm{~nm}$, entrainment may occur for different wavelength radiations. Aguzzi et al. (2008) suggested that monochromatic blue light alone controls the behavioural rhythms of $N$. norvegicus. We are working under this hypothesis since $N$. norvegicus has a wide depth range of distribution in the Mediterranean (encompassing shelves and slopes) and animals of all depths must be capable of synchronising their diel behaviour with the light intensity cycle of this radiation, as all other radiations are progressively scattered and absorbed in the water column (Jerlov, 1968; Herring, 2002).

We showed that burrow emergence rhythms weakened in constant darkness. Animals' activity rhythms show a weak circadian component (Fig. 3B) under these conditions, as a marker of biological clock entrainment (Redlin and Morosovsky, 2004). Activity rhythm testing in constant darkness was not performed in animals previously exposed to pho- toperiod cycles of brighter intensity (Aguzzi et al., 2008), so the entrainment capability of $N$. norvegicus at different depths remains today unknown.

The observation that constant darkness disrupts the rhythmic pattern of activity is of interest in relation to the ecology of the species. The presence of burrows in laboratory setups should strengthen the expression of locomotor rhythms in endobenthic (i.e. burying and burrowing) decapods independently from the presence or absence of a reference photoperiod cycle (Atkinson and Naylor; 1973; Williams et al., 1985; Westin and Gydemo, 1988). These structures often induce behavioural quiescence (Moller and Jones, 1975). Nevertheless, our data indicate that the alternation of scoto- and photophase rather than burrow presence alone plays a consolidating role in the structuring of locomotor activity rhythms of $N$. norvegicus.

Distances covered in activity timing cannot be computed with precision by actigraphic techniques. In this study, we obtained locomotor data sets, in centimetres, of the distance covered by the centroid of the binarised animal object. We used these data to calculate the total distance covered by animals during their excursion, reporting an overall maximum distance of nearly $20 \mathrm{~m}$ per day (i.e. animal no. 8; see Fig. 5). We also reported marked inter-individual variability in emergence behaviour, which may account for differences in computed demographic estimates by trawling and by other sampling systems, such as burrow counting (Chapman, 1980). The locomotor performances were tested in rectangular individual aquaria and not in large tanks with multiple burrows. As a consequence, the results from our experimental setting are difficult to extrapolate to the field at present. Future experiments performed in collective tanks should determine whether animal movement occurs in straight lines from the burrow mouth (as observed in the present experiments) or is performed in other fashions, such as around the burrow mouth. Nonetheless, the possibility of inferring distances covered by animals within environmental limiting conditions, such as those of our experiment, opens interesting possibilities for calculating the potential extension of the seabed parcel around animal burrows.

Video-image analysis can be used to study locomotor changes as a marker of modifications in overt activity of the central nervous system (Rodland et al., 2006; Ramazani et al., 2007; Shih and You ng, 2007). In this study, we have presented a new 
automated video-image analysis system for studying burrow emergence rhythms for marine endobenthic species of significant commercial and ecological importance. Our goal was to track the emergence behaviour in terms of centroid position changes between consecutive digital frames (Togasaki et al., 2005).We developed a user-friendly system for acquiring and processing images of several animals contemporarily, over a long period of time, from low-cost USB infrared web cameras and customised processing software. As an example of the applicability of our technique, we not only analysed data with different statistical tools of chronobiology (i.e. double-plot actograms, periodograms, and waveform and Fourier analysis), but we also computed activity parameters, such as the time in burrow and total distances covered during excursion, which could not be easily estimated by actigraphy. The feasibility of our study suggests that video-image analysis may in the near future partially replace actigraphy and telemetry in the field of neuroscience due to its reduced hardware costs and technical constraints (Lee and Szema, 2005; Steger et al., 2007).

\section{ACKNOWLEDGEMENTS}

We thank Dr K. Last (The Scottish Association for Marine Science-SAMS) and Prof. R.J.A. Atkinson (University of Glasgow) for their valuable comments during the revision of this manuscript. This work was financed by the NORIT project (CTM20055-02034/MAR) funded by the Spanish Ministry of Education (CYCT, MEC). Jacopo Aguzzi is a Postdoctoral Fellow of the "Juan de la Cierva" Programme (Education and Science Ministry-MEC, Spain).

\section{REFERENCES}

Aguzzi, J., D. Sarriá, J.A. García, J. Del Rio, F. Sardà and A. Manuel. - 2008. A new tracking system for the measurement of diel locomotor rhythms in the Norway lobster, Nephrops norvegicus (L.). J. Neurosci. Met., 173: 215-224.

Aguzzi, J. and J Chiesa. - 2005. Cardiac activity of Nephrops norvegicus (Decapoda: Nephropidae): the relationships between circadian and ultradian rhythms. J. Crustac. Biol., 25: 577-584.

Aguzzi, J., J.B. Company and P. Abelló. - 2004. Locomotor activity rhythms of continental slope Nephrops norvegicus (Decapoda: Nephropidae). J. Crustac. Biol., 24: 282-290.

Aguzzi, J. and F. Sardà. - 2008. A history of recent advancements on Nephrops norvegicus behavioral and physiological rhythms. Rev. Fish Biol. Fish., 18: 235-248.

Aguzzi, J., F. Sardà, P. Abelló, J.B. Company and G. Rotllant. - 2003. Diel and seasonal patterns of Nephrops norvegicus
(Decapoda: Nephropidae) catchability in the western Mediterranean. Mar. Ecol. Prog. Ser., 258: 201-211.

Aguzzi, J., J. Chiesa, P. Abelló and A. Diez-Noguera. - 2005. Temporal modification in cardiac rhythmicity of Nephrops norvegicus (Crustacea: Decapoda) in relation to trawl capture stress. Sci. Mar., 69(3): 369-374

Aguzzi, J., J.J. Chiesa, R. Caprioli, D. Cascione, G. Magnifico, V. Rimatori and C. Costa. - 2006. Preliminary evidences of circadian fan activity rhythm in Sabella spallanzanii (Gmelin, 1791) (Polychaeta: Sabellidae). Sci. Mar., 70(4): 727-734

Andersen, F.S. - 1962. The Norway lobster in the Faroe waters. Medd. Dan. Fisk. Havunders. 3: 365-326.

Aréchiga, H., R.J.A. Atkinson and J.A. Williams. - 1980. Neurohumoral basis of circadian rhythmicity in Nephrops norvegicus (L.). Mar. Behav. Physiol., 7: 185-197.

Atkinson, R.J.A. and E. Naylor. - 1973. Activity rhythm in some burrowing decapods. Helgoländer wiss. Meeresunters, 24: 192-201.

Atkinson, R.J.A. and E. Naylor. - 1976. An endogenous activity rhythm and the rhythmicity of catches of Nephrops norvegicus (L.). J. Exp. Mar. Biol. Ecol., 25: 95-108.

Bell, M.C., F. Redant, and I. Tuck. - 2006. Nephrops species. In: B.F. Phillips (ed.), Lobsters: biology, management, aquaculture and fisheries. Blackwell Publishing, Oxford.

Canal-Corretger, M.M., J. Vilaplana, T. Cambras and A. DíezNoguera. - 2001. Functioning of the rat circadian system is modified by light applied in critical postnatal days. Am. J. Physiol. Reg. Integ. Comp. Physiol., 280: 1023-1030.

Chapman, C.J. - 1980. Ecology of juvenile and adult Nephrops. In: J.S. Cobb and B.F. Phillips (eds.). The biology and management of lobsters. pp. 143-178. Academic Press, New York.

Chapman, C.J., A.D.F. Johnstone and A.L. Rice. - 1975. The behaviour and ecology of the Norway lobster Nephrops norvegicus (L). $9^{\text {th }}$ Proc. Eur. Mar. Biol. Symp.: 59-74.

Chapman, C.J., R. Pristley and H. Robertson. - 1972. Observations on the diurnal activity of the Norway lobster Nephrops norvegicus (L.). ICES, C.M/K 20.

Costa, C., A. Loy, S. Cataudella, D. Davis and M. Scardi. - 2006. Extracting fish size using dual underwater cameras. Aquac. Eng., 35: 218-227.

Cristo, M. and M. Castro. - 2005. Field estimation of daily ration of Norway lobster (Nephrops norvegicus) in the south of Portugal. N. Z. J. Mar. Freshw. Res., 39: 485-491.

Cronin, T.W. - 1986. Photoreception in marine invertebrates. Amer. Zool., 26: 403-415.

Edwards, D.H. - 1984. Crayfish extraretinal photoreception. I. Behavioural and motoneuron responses to abdominal illumination. J. Exp. Biol., 109: 291-306.

Emery, P., R. Sranewsky, C. Helfrich-Foster, M. Emery-Le, J. Hall and M. Rosbash. - 2000. Drosophila CRY is a deep brain circadian photoreceptor. Neuron, 26. 493-504.

Fanjul-Moles, M.L., E.G. Escamilla-Chimal, A. Gloria-Soria and G. Hernández-Herrera. - 2004. The crayfish Procambarus clarkii CRY shows daily and circadian variation. J. Exp. Biol., 207: 1453-1460.

Farmer, A.S.D. - 1974. Burrowing behaviour of the Norway lobster, Nephrops norvegicus (L.) (Decapoda: Nephropidae). Estuar. Coast Mar. Sci., 2: 49-58.

Farmer, A.S.D. - 1975. Synopsis of biological data on Norway lobster, Nephrops norvegicus (Linneo 1758). FIRS/S, 112.

Fernández de Miguel, F. and H. Aréchiga. - 1994. Circadian locomotor activity and its entrainment by food in the crayfish Procambarus clarkii. J. Exp. Biol., 190: 9-21.

Gaten, E., P.M.J. Shelton, C.J. Chapman and A.M. Shaks. - 1990. Depth related variation in the structure and functioning of the compound eye of the Norway lobster Nephrops norvegicus. J. Mar. Biol. Ass. U.K., 70: 343-355.

Herring, P. - 2002. The Biology of the Deep Ocean. Oxford University Press, Oxford.

Jerlov, N.G. - 1968. Optical Oceanography. Elsevier, Amsterdam.

Lee, L.P. and R. Szema. - 2005. Inspirations from Biological Optics for Advanced Photonic Systems. Science, 310: 1148-1150.

Levine, J.D., P. Funes, H.B. Dowse and J.C. Hall. - 2002. Signal analysis of behavioral and molecular cycles. B.M.C. Neurosci., 3: 1 .

Loew, E.R. - 1974. Light-induced rhabdometric degeneration in the Norway lobster, Nephrops norvegicus (L.). ICES, C.M./K 29. 
Moller, T.H. and D.A. Jones. - 1975. Locomotor rhythms and burrowing habits of Penaeus semisulcatus (de Haan) and $P$. monodon (Fabricius) (Crustacea: Penaeidae). J. Exp. Mar. Biol. Ecol., 18: 61-77.

Moller, T.H. and E. Naylor. - 1980. Environmental influence on locomotor activity in Nephrops norvegicus (Crustacea:Decapoda). J. Mar. Biol. Ass. U.K., 60: 103-113.

Naylor, E. - 2005. Chronobiology: implications for marine resources exploitation and management. Sci. Mar., 69(Suppl. 1): 157-167.

Oakley, S.G. - 1979. Diurnal and seasonal changes in the timing of peak catches of Nephrops norvegicus reflecting changes in behaviour. In: E. Naylor and R.G. Hartnoll (eds.), Cyclical phenomena in marine plants and animals, pp. 367-373. Pergamon Press, Oxford and New York.

Ramazani, R, H.R. Krishnan, S.E. Bergeson and N. Atkinson. -2007. Computer automated movement detection for the analysis of behaviour. J. Neurosci. Met., 162: 171-179.

Redlin, U. and N. Morosovsky. - 2004. Nocturnal activity in a diurnal rodent (Arvicanthis niloticus): The importance of masking. J. Biol. Rhythms, 19: 58-67.

Refinetti, R. - 2006. Circadian physiology. Francis and Taylor, New York.

Rodland, DL, B.R. Schone, S. Helema, J.K. Nielsen and S. Baier. -2006 . A clockwork mollusc: Ultradian rhythms in bivalve ac- tivity revealed by digital photography. J. Exp. Mar. Biol. Ecol., 334: 316-323.

Salat, J. - 1996. Review of hydrographyc environmental factors that may influence anchovy habitats in northwestern Mediterranean. Sci. Mar., 60(Suppl 2): 21-32.

Shih, Y. H. and M. S. Young. - 2007. Integrated digital image and accelerometer measurements of rat locomotor and vibratory behaviour. J. Neurosci. Met., 166: 81-88.

Steger, C., M. Ulrich and C. Wiedemann. - 2007. Machine vision algorithms and applications. Wiley V.C.H., Berlin.

Togasaki, D.M., A. Hsu, M. Samant, B. Farzan, L.E. DeLanney, J.W. Langston, D. Di Monte and M. Quik. - 2005. The webcam system: a simple automated, computer based video system for quantitative measurement of movement in nonhuman primates. J. Neurosci. Met., 145: 159-166.

Westin, L., R. Gydemo. - 1988. The locomotor activity patterns of juvenile crayfish (Astacus astacus) and effect of shelter availability. Aquaculture, 68: 361-367.

Williams, B.G., E. Naylor and T.D. Chatterton. -1985 . The activity patterns of New Zealand mud crabs under field and laboratory conditions. J. Exp. Mar. Biol. Ecol., 89: 269-282.

Scient. ed.: C. Zeng

Received November 5, 2008. Accepted February 19, 2009.

Published online September 1, 2009. 